non-steroidal anti-inflammatory drugs, $20 \%$ had at least one local corticosteroid infiltration, $34 \%$ had functional rehabilitation and $4,1 \%$ had surgical treatment. Regarding sexual dysfunction, $34.5 \%$ of our patients didn't have any sexual activity, $2.1 \%$ had a catastrophic sexual life (score <20), $9 \%$ had a disappointing sexual life (score between 20 and 40 ), $20 \%$ had an average sexual life (score between 40 and 60 ), 17.9\% had a satisfying sexual life (score between 60 and 80 ), while only $13.1 \%$ had a very fulfilling sexual life (score between 80 and 100. we showed that the alteration of the sexual quotient in our patients is more marked when the age of the patients is more advanced. But we didn't found a significant correlation with the duration of the disease, the mean visual analogue scale for pain and the functional scores of Quebec and Dallas.

Conclusions: Our study suggests that sexuality is profoundly disrupted in chronic low back pain. The advanced age is proved to be correlated with the deterioration of the sexual life. So, sexuality must be taken into account in the management of patients with chronic low back pain.

References:

[1] Kellie S.H. Kwan, Lindy J. Roberts, Delphin M. Swalm

[1] Sexual dysfunction and chronic pain: the role of psychological variables and impact on quality of life.

[2] European Journal of Pain 9 (2005) 643-652.

[2] Ambler Nicholas, Williams Amanda, Hill Patrick, Gunary Rachel, Cratchley Gina.

[3] Difficultés sexuelles des patients douloureux chroniques.

[4] Clinical Journal of Pain 17 (2001) pp 138-145.

Disclosure of Interest: None declared

DOI: 10.1136/annrheumdis-2017-eular.5339

\section{SAT0599 LOW BACK PAIN IN MEDICAL STUDENTS LINKED TO POOR SLEEP QUALITY: RESULTS FROM THE PAX-I STUDY}

N.R. Ziade ${ }^{1,2}$, F. Fayad ${ }^{1}$, B. Badra ${ }^{3} .{ }^{1}$ Rheumatology, Hotel Dieu de France

${ }^{2}$ Rheumatology; ${ }^{3}$ Medicine, St-Joseph University, Beirut, Lebanon

Background: Low Back Pain (LBP) is a major public health problem and is classified by the Global Burden of Disease Study among the ten diseases most responsible for Disability-Adjusted Life Years worldwide. All ages may be affected, mostly young adults, with a prevalence going up to $50 \%$. Medical students may be particularly vulnerable due to sedentary lifestyle and high stress levels.

Objectives: The primary objective is to evaluate the prevalence of LBP in Lebanese medical students. The secondary objective is to identify predictive factors associated with LBP and to identify prevalence and components of inflammatory back pain (IBP).

Methods: PAX-I is a cross-sectional study, completed at the St-Joseph University of Beirut from April to June 2016. All students from the first to the sixth year of medicine were invited to fill a questionnaire about their demographic data, lifestyle habits, Patient Health Questionnaire for Depression and Anxiety (PHQ4) and LBP characteristics, including components of IBP as per ASAS criteria. Student test and ANOVA were used for quantitative variables, chi-square test was used for qualitative variables and logistic regression was used for predictive factors for low back pain. Analysis were performed on IBM SPSS Statistics 23

Results: Response rate was $51.3 \%$ (258/502). Mean age was 20.86 years (SD 1.92). $54.3 \%$ were female, $76.7 \%$ drank caffeine, $66.3 \%$ had a regular sports activity and $9.7 \%$ were smokers. $38 \%$ had the habit of walking while studying. All habits were similar across years of studying except for sports activities which decreased over the years ( $p$ 0.018). 80\% were satisfied with their studies. Only $46 \%$ were satisfied with their quality of sleep. Mean PHQ4 score was 7.17 and increased with the years of studies ( $p$ 0.045).

$55.8 \%$ of students reported a LBP event during the past year, with a mean number of 3.6 episodes per year. $91 \%$ of these students had LBP while studying, with high reported intensity (5.18/10), 62.5\% reported LBP after exercise. $80 \%$ had episodes of less than one month and $7 \%$ of more than three months duration. 12\% had IBP according to the ASAS criteria (Details of IBP in Figure 1). Predictive factors for LBP in univariate analysis were: smoking ( $p 0.040)$, alcohol consumption ( $p$ 0.005), caffeine consumption ( $p$ 0.041), television watching ( $p$

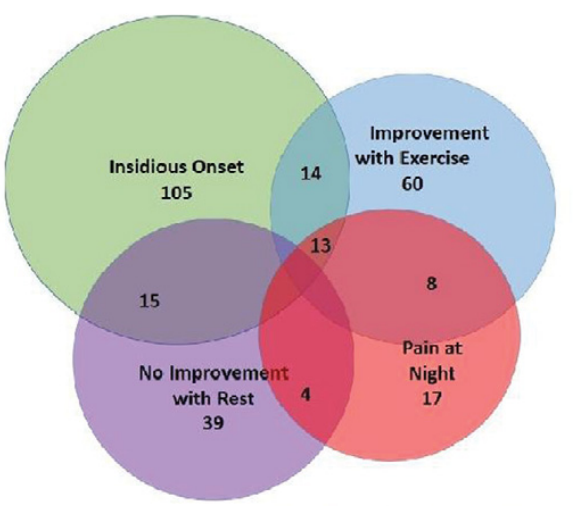

Figure 1. Components of Inflammatory Back Pain according to the A5AS criteria
0.042 ) -positive association-, and number of hours of sleep ( $p$ 0.011) and satisfaction with sleep quality-negative association- ( $p$ 0.017). Satisfaction with sleep quality remained the only significant association in multivariate analysis ( $p$ 0.014).

Conclusions: LBP is a frequent problem among medical students with high intensity, especially when studying, and a high recurrence rate. The main predictive factor was poor satisfaction with sleep quality. A significant percentage fulfills IBP criteria by auto-questionnaire and should benefit from further investigation.

References:

[1] Hoy D et al. The global burden of low back pain: estimates from the Global Burden of Disease 2010 study. Ann Rheum Dis 2014;968-74.

[2] Sieper $J$ et al. New criteria for inflammatory back pain in patients with chronic back pain: a real patient exercise by experts from the Assessment of SpondyloArthritis International Society (ASAS). Ann Rheum Dis 2009;68:784-

Disclosure of Interest: None declared

DOI: 10.1136/annrheumdis-2017-eular.3025

\section{SAT0600 USEFULNESS OF VERTEBROPLASTY IN VERTEBRAL FRACTURES WITH PERSISTANT BACK PAIN. A REPORT OF 64 VERTEBRAL AUGMENTATION FROM A UNIVERSITY HOSPITAL}

O. Fernandez-Berrizbeitia ${ }^{1}$, M. González-de-Garay-Sanzo ${ }^{2}$, A. López-Medina ${ }^{2}$ M. García-Vivar ${ }^{1}$, E. Ruíz-Lucea ${ }^{1}$, I. Torre-Salaberri ${ }^{1}$, A. Intxaurbe-Pellejero ${ }^{1}$,

J. Blanco-Madrigal ${ }^{1}$, E. Guerrero-Basterretxea ${ }^{1}$, I. Calvo-Zorrilla ${ }^{1}$

O. Ibarguengoitia-Barrena ${ }^{1}$, C. Pérez-Velásquez ${ }^{1}$, L. Estopiñán-Fortea ${ }^{1}$,

C. Gómez-Arango ${ }^{1}$, N. Rivera-García ${ }^{1}$, M. Allande-López-Linares ${ }^{1}$,

A. Bilbao-González ${ }^{3}$, E. Galíndez-Aguirregoikoa ${ }^{1} .{ }^{1}$ Rheumatology;

${ }^{2}$ Radiodiagnostic; ${ }^{3}$ Research, Basurto University Hospital, Bilbao, Spain

Background: Management options for patients with persistent back pain after a vertebral fracture include vertebral augmentation, but its use is controversial.

Objectives: Our iam was to evaluate the fracture cause, efficacy and complications of consecutive vertebroplasties performed in our Hospital in a 12 years period.

Methods: Retrospective study of vertebroplasties performed at a University Hospital in the last 12 years (April 2004 to April 2016). The duration of follow-up was more than 12 months. Epidemiological variables, indications, time elapsed, efficacy and complications of the procedure were collected. The indication of vertebroplasties in fractures was pain refractory to usual symptomatic treatment in these pathologies: osteoporosis, trauma, leukemia/lymphoma, metastasis and hemangioma. Efficacy was assessed at 6 and 12 months with a simple verbal scale according to the pain response (improvement/non-improvement). Patients who died before 12 months period were excluded for the that parameter. A comparative study of the efficacy between a)cause of fracture, b)location, c)time elapsed, d)access route and e)complication was performed. For the descriptive analysis we used frequencies and percentages in the case of qualitative variables, and mean and standard deviation (SD) or median and interquartile range for quantitative variables. Chi-square test or Fisher's exact test was used in for qualitative variables, and Wilcoxon's non-parametric test for evolution time. Statistic analysis was performed with the SAS System for Windows V 9.2 .

Results: 66 vertebroplasties were performed in 44 patients $(75 \%$ female/25\%

\begin{tabular}{|l|l|}
\hline FRACTURE CAUSE, n(\%) & \\
\hline Osteoporosis & $50(78.13)$ \\
Trauma & $6(9.38)$ \\
Lynphoma/leukemia, $n(\%)$ & $5(7.81)$ \\
Metastasis & $2(3.13)$ \\
Hemangioma & $1(1.56)$ \\
\hline FRACTURE LEVEL, n(\%) & \\
\hline Lumbar & $25(39.06)$ \\
Dorsal & $37(57.81)$ \\
Cervical & $2(3.13)$ \\
\hline VERTEBROPLASTY ACCESS ROUT, n(\%) & \\
\hline Unipedicular: & $15(23.44)$ \\
Ripedicular & $44(68.75)$ \\
Rarapedicular & $2(3.13)$ \\
Spine-Jack & $1(1.56)$ \\
Anterior & $2(3.13)$ \\
\hline CEMENT LEAKAGE, n(\%) & \\
\hline No & $38(59.38)$ \\
Mild & $20(31.25)$ \\
Mloderate & $5(7.81)$ \\
Sexere & $1(1.56)$ \\
\hline REFRACTURE, n(\%) & \\
\hline No & \\
\hline Yes & $56(87.5)$ \\
\hline EFFICACY AT 6 MONTHS/12 MONTHS, n(\%) & $8(12.5)$ \\
\hline Improvement & $38(59.38) / 43(75.44)$ \\
Lack of improvement & $26(40.63) / 14(24.56)$ \\
\hline
\end{tabular}

